\title{
CARDIOMETABOLIC RESPONSES OF BODY-WEIGHT EXERCISES WITH AND WITHOUT VIBRATION
}

\author{
Jie Kang, Nicholas A. Ratamess, Jeremy Kuper, Elizabeth O'Grady, Nicole Ellis, \\ Ira Vought, Jill A. Bush, and Avery D. Faigenbaum \\ Human Performance Laboratory, Department of Health and Exercise Science, \\ The College of New Jersey, Ewing, New Jersey, USA
}

\author{
Original scientific paper \\ https://doi.org/10.26582/k.51.1.12
}

\begin{abstract}
:
This investigation examined the interactive effect of body-weight (BW) exercises and vibration on cardiometabolic responses. Fourteen subjects performed a BW exercise protocol with $(B W+V)$ and without $(\mathrm{BW}-\mathrm{V})$ vibration in a randomized order. The BW exercise protocol consisted of three circuits of eight calisthenics-based exercises including prisoner squat, push-up, isometric squat, reverse dip, lunge, flutter kicks, isometric lunge, and T push-up. Vibratory frequency and amplitude were set at $40 \mathrm{~Hz}$ and $4 \mathrm{~mm}$, respectively. Oxygen uptake $\left(\mathrm{VO}_{2}\right)$, heart rate $(\mathrm{HR})$, expired ventilation $\left(\mathrm{V}_{\mathrm{E}}\right)$, and blood lactate $[\mathrm{La}]$ were determined during the protocol and 30-minute recovery. The mean $\mathrm{VO}_{2}$ reached $48 \%$ and $50 \%$ of $\mathrm{VO}_{2} \mathrm{max}$ and the mean $\mathrm{HR}$ reached $80 \%$ and $83 \%$ of $\mathrm{HRmax}$ in $\mathrm{BW}-\mathrm{V}$ and $\mathrm{BW}+\mathrm{V}$, respectively. During the protocol, while the mean $\mathrm{V}_{\mathrm{E}}$ was greater $(\mathrm{p}=.031)$ in $\mathrm{BW}+\mathrm{V}$ than $\mathrm{BW}-\mathrm{V}$, no differences were seen for $\mathrm{VO}_{2}$ and $\mathrm{HR}$ between the two conditions. During recovery, while mean $\mathrm{VO}_{2}$ was greater $(\mathrm{p}=.002)$ in $\mathrm{BW}+\mathrm{V}$ than $\mathrm{BW}-\mathrm{V}$, no differences were seen for $\mathrm{V}_{\mathrm{E}}$ and $\mathrm{HR}$ between the two conditions. [La] values were significantly elevated but remained similar between the two conditions. Exercise-specific $\mathrm{VO}_{2}$ was higher during the prisoner squat $(\mathrm{p}=.003)$ and isometric squat $(\mathrm{p}=.042)$ in $\mathrm{BW}+\mathrm{V}$ than $\mathrm{BW}-\mathrm{V}$, while no differences in $\mathrm{VO}_{2}$ were observed for all other exercises. Performing three circuits of eight BW exercises in a rapid-and-intense manner produced a sufficient increase in cardiometabolic responses. Metabolic potentiation associated with combining vibration with BW exercises seemed to be influenced by how the exercises were carried out on a vibration plate.
\end{abstract}

Key words: metabolic demand, oxygen uptake, expiratory ventilation, heart rate, blood lactate

\section{Introduction}

In recent worldwide surveys administered among fitness professionals, body-weight (BW) exercise has been viewed as one of the top fitness trends (Thompson, 2016, 2017). BW exercises, such as BW squat, push-ups, jumps, and planks, require little or no exercise equipment and rely on one's own body mass as a source of resistance. As a result, BW exercises can be carried out virtually anywhere. BW exercises can also be combined with plyometrics and agility drills, making them an alternative training method for athletes (Ratamess, et al., 2015). They may also help mitigate boredom in training through a greater variety of movement options (Thompson, 2017). Training that incorporates BW exercises has been shown to improve cardiovascular fitness and muscular strength and endurance (Buckley, et al., 2015; McRae et al., 2012; Myers, Schneider, Schmale, \& Hazell, 2015), to maintain balance, flexibility, and cognitive function in elderly (Kendall \& Fairman,
2014; Seguin \& Nelson, 2003), and to help break up sedentary time and thus increase energy expenditure (Carter, Jones, \& Gladwell, 2015). Ratamess et al. (2015) have previously examined the metabolic cost of selected BW exercises including burpees, planks, and push-up variations. It was found that burpees, a full body exercise consisted of squatting, thrusting, plank, and jumping, exhibited the highest metabolic demand with mean oxygen uptake $\left(\mathrm{VO}_{2}\right)$ reaching $23 \mathrm{ml} \cdot \mathrm{kg}^{-1} \cdot \mathrm{min}^{-1}$ or $48 \%$ of $\mathrm{VO}_{2}$ max when performed for three sets of 10 repetitions with 2-minute rest intervals. Still, the cardio-metabolic demand of many other forms of BW exercise used today, especially when done in a successive order and an intense manner, remains unknown.

A BW exercise such as the squat with and without additional loads can also be performed concurrently with vibration. This combined approach has been shown to not only enhance strength and power (Giombini, et al., 2013; Luo, McNamara, \& 
Moran, 2005; Marín \& Rhea, 2010a, 2010b), but also improve bone density, balance, and flexibility (Cochrane, 2011; Rittweger, 2010). In this approach, vibration is applied through a vibration plate and then transmitted through parts of the body to the target muscle groups. Vibration training has been shown to increase stretch-shortening action of skeletal muscles as evidenced by an increased magnitude of electromyography measured during vibration exposure (Bosco, Cardinale, \& Tsarpela, 1999; Cardinale \& Lim, 2003). Such enhanced muscle reflexes can evoke sufficient muscular work to raise whole-body oxygen uptake $\left(\mathrm{VO}_{2}\right)$. Rittweger, Schiessl, and Felsenberg (2001) observed that whole-body vibration performed by BW squats at frequency of $26 \mathrm{~Hz}$ and an amplitude of $6 \mathrm{~mm}$ could increase $\mathrm{VO}_{2}$ to values comparable to brisk walking. Kang et al. (2016a, 2016b) also demonstrated that this same BW exercise performed on a vibration plate with a vibratory load of $40 \mathrm{~Hz}$ and $4 \mathrm{~mm}$ could increase $\mathrm{VO}_{2}$ by $\sim 10 \%$.

A variety of $\mathrm{BW}$ exercises has been created that use a vibration plate as an additional training stimulus. In these exercises, an individual may experience either the whole-body (i.e., BW squats) or partial vibration through either the upper- (i.e., push-ups) or lower-body extremities (i.e., lunges). However, efficacy of this combined approach remains questionable. This is because the evidence that supports the use of vibration is only limited to certain body movements. For example, studies based on BW squats have demonstrated a further increase in $\mathrm{VO}_{2}$ following vibration of sufficient amplitude (i.e., $4 \mathrm{~mm}$ ) and frequency (i.e., $40 \mathrm{~Hz}$ ) (Kang, et al., 2016a, 2016b). Given that BW exercise training often consists of multiple exercises done successively in a sequence, it is necessary to determine how vibration may interact with BW exercises in this more complex scenario.

The present investigation was undertaken to compare cardiometabolic responses to BW exercises with and without concurrent vibration. The experimental design involved three sets of eight different BW exercises performed successively in high-intensity intervals with and without vibration monitored by a continuous recording of physiological parameters both during and after each exercise protocol. It was hypothesized that 1) multiple BW exercises performed in an intense and successive manner can pose a sufficiently high cardiometabolic demand, and 2) performing BW exercises concurrently with vibration would further augment cardiometabolic responses than performing BW exercises alone.

\section{Materials and methods}

\section{Subjects}

Fourteen subjects, including eight men and six women, volunteered to participate in this study. These subjects were untrained but healthy, free of any orthopedic injury, and they did not take any medications, anabolic steroids, or nutritional supplements known to affect exercise performance as revealed by their responses to a medical and physical activity questionnaire. All subjects had prior experience with the BW exercises selected. However, none of them had trained consistently using these BW exercises. In addition, no subject had prior experience of using a vibration device. Subjects were informed of the purpose and testing procedures of the study and each gave their written consent to participate. All experimental procedures were evaluated and approved by the Institutional Review Board for Human Subjects Experimentation. The physical and physiological characteristics of subjects are presented in Table 1.

\section{Experimental design}

Each subject completed a familiarization session, a $\mathrm{VO}_{2} \max$ test, and two BW exercise protocols on four different days. In each of the two BW exercise protocols, subjects performed three circuits of eight BW exercises, but in one they did it with vibration $(\mathrm{BW}+\mathrm{V})$ and in the other without it $(\mathrm{BW}-\mathrm{V})$. The order in which the two exercise protocols were performed was randomized. Vibration was provided by a Power Plate ${ }^{\circledR}$ (Power Plate North America Inc., Northbrook, IL). Frequency and amplitude of vibration were set at $40 \mathrm{~Hz}$ and

Table 1. Physical and physiological characteristics of subjects

\begin{tabular}{lccc}
\hline Variables & Men & Women & Combined \\
\hline Sample size & 8 & 6 & 14 \\
Age (year) & $21.1 \pm 1.0$ & $20.5 \pm 1.2$ & $20.9 \pm 1.1$ \\
Body mass $(\mathrm{kg})$ & $86.5 \pm 7.4$ & $65.1 \pm 3.2$ & $77.3 \pm 12.4$ \\
Height $(\mathrm{cm})$ & $181.7 \pm 4.8$ & $165.1 \pm 2.97$ & $174.6 \pm 9.4$ \\
$\%$ Fat & $12.1 \pm 1.8$ & $21.6 \pm 4.2$ & $15.4 \pm 5.5$ \\
VO $_{2}$ max $\left(\mathrm{ml} \cdot \mathrm{kg}^{-1} \cdot \mathrm{min}^{-1}\right)$ & $46.79 \pm 6.75$ & $44.22 \pm 5.45$ & $45.65 \pm 6.14$ \\
HRmax (beats $\left.\cdot \mathrm{min}^{-1}\right)$ & $193.5 \pm 11.8$ & $200.2 \pm 5.3$ & $196.4 \pm 9.9$ \\
\hline
\end{tabular}

Note. Data are expressed in means \pm SD. 
$4 \mathrm{~mm}$, respectively. Physiological parameters such as $\mathrm{VO}_{2}$, heart rate $(\mathrm{HR})$, expired ventilation $\left(\mathrm{V}_{\mathrm{E}}\right)$, and respiratory exchange ratio (RER) were measured continuously throughout the protocol as well as during 30 min post exercise. All experimental trials were conducted in a 3-hour post-absorptive state and separated by at least 48 hours in between trials. On the day prior to each protocol, subjects were instructed to avoid any vigorous activities, to refrain from alcohol and caffeine consumption, and to follow their usual diets.

\section{Familiarization session}

Subjects attended a familiarization session prior to the start of the study. During this session, instructions related to testing protocols, instrumentation, and measurements were provided. Body mass, height, and percent body fat were also determined for each subject. Body mass and height were measured using an electronic weight scale and a wallmounted stadiometer, respectively. Percent body fat (\%fat) was measured by the same researcher that had experience in 3-site skinfold techniques as described by Jackson and Pollock, (1978) and Jackson, Pollock, and Ward, (1980); \%fat was calculated using the equation of Siri (1956). Subjects were given the opportunity to practice BW exercises with a vibration plate and to familiarize with the procedure involved in $\mathrm{VO}_{2} \max$ test. In this session, subjects also received instructions regarding physical activity and dietary guidelines that they would need to follow prior to each protocol.

\section{$\mathrm{VO}_{2}$ max test}

$\mathrm{VO}_{2}$ max was assessed using a progressive, multi-stage ramp protocol on a treadmill using a metabolic system (ULTIMA Metabolic System, MedGraphics Corporation, St. Paul, MN). The protocol consisted of a general warm-up of walking at $3.5 \mathrm{mph}$ followed by running at $6.0 \mathrm{mph}$ with percent grade increased by $2.5 \%$ every two minutes. All subjects were verbally encouraged to continue exercise until volitional exhaustion. The test was considered valid when the subjects met at least two of the following three criteria: an increase in $\mathrm{VO}_{2}$ of less than $100 \mathrm{ml} \cdot \mathrm{min}^{-1}$ despite an increase in work load, a RER value greater than 1.15, and a peak HR reaching within $10 \%$ of age-predicted maximal $\mathrm{HR}$. Breath-by-breath $\mathrm{VO}_{2}$ data were obtained and $\mathrm{VO}_{2}$ max was determined by recording the highest measure.

\section{BW exercise protocols with and without vibration}

Upon arrival, each subject was fitted for a mask and a HR monitor and connected to the metabolic system for habituation. They were then positioned on a reclining chair and laid quietly for $10 \mathrm{~min}$ prior to a 3-min baseline measurement that included resting metabolic rate and blood lactate concentrations ([La]).

After a brief warm-up consisting of 3 minutes of stationary cycling and light stretching, the subjects performed a BW exercise protocol either with or without vibration while being attached to the metabolic system and wearing a HR monitor. The BW exercise protocol consisted of three circuits of eight calisthenics-based exercises with a 2-minute rest interval in between sets. The eight exercises chosen and performed in the same order within each set were prisoner squat, push-up, isometric squat, reverse dip, lunge, flutter kicks, isometric lunge, and $\mathrm{T}$ push-up. These exercises are commonly used in fitness workouts and are similar to those designed by the manufacturer of the Power Plate ${ }^{\circledR}$. Instructions as to how each BW exercise should be performed using a vibration plate are shown in Table 2. Vibration was provided using a Power Plate ${ }^{\circledR}$ (Power Plate North America Inc., Northbrook, IL) and frequency and amplitude of vibration were set at $40 \mathrm{~Hz}$ and $4 \mathrm{~mm}$, respectively. This vibratory load has been shown to be effective in augmenting metabolic responses both during and after body weight squats (Kang, et al., 2016a,2016b). For all exercises, subjects were encouraged to complete as many repetitions as possible within 20 -second intervals followed by a 10 -second rest period before proceeding to the next exercise in the sequence. This intermittent pattern is known as Tabata intervals (Tabata, et al., 1996, 1997). For each exercise, total numbers of repetitions were recorded and only those repetitions that met the criteria shown in Table 2 were counted. The entire protocol took $\sim 16$ min to complete. Upon completion of the protocol, subjects sat quietly for an additional $30 \mathrm{~min}$. Physiological parameters, including $\mathrm{VO}_{2}, \mathrm{HR}, \mathrm{V}_{\mathrm{E}}$, and RER, were measured continuously throughout the exercise session and the 30 -minute recovery period. Peak [La] were determined immediately after the protocol was completed. All exercise sessions were individually supervised by a certified strength and conditioning specialist to insure proper execution of BW exercises.

Due to the fact that vibration plate is 25 $\mathrm{cm}$ above the ground, an additional floor area surrounding the device was built to the same height as the vibration plate by using step benches. This platform allowed for BW exercises to be performed with normal techniques without having to be altered due to uneven grounds. BW exercises without vibration were conducted on the floor that had the similar surface as the platform. Our pilot testing revealed that BW exercises done on both surfaces produced the identical $\mathrm{VO}_{2}$ and $\mathrm{HR}$. This experimental set-up allowed for adequately assessing of cardiometabolic demands of BW exercises while also enabling researchers to accurately examine the potential additive effects of vibration. 
Table 2. Description of body-weight exercises performed with a vibration plate

\begin{tabular}{|c|c|}
\hline Exercises & Description \\
\hline & $\begin{array}{l}\text { Prisoner squats } \\
\text { - The subject stands with feet shoulder-width apart and hips slightly externally rotated on the } \\
\text { vibration plate and places hands behind the head. } \\
\text { - A repetition begins as the subject lowers into a squat position with thighs parallel to the floor } \\
\text { and then returns to the standing position. }\end{array}$ \\
\hline & $\begin{array}{l}\text { Push-ups } \\
\text { - The subject keeps in a prone position with the back straight, the hands palms down shoulder- } \\
\text { width apart on the vibration plate. } \\
\text { - A repetition begins as the subject lowers the body while keeping back flat until the chin nearly } \\
\text { touches the plate and then pushes back to the starting position. }\end{array}$ \\
\hline & $\begin{array}{l}\text { Isometric squats } \\
\text { - The subject stands with feet shoulder-width apart and hips externally rotated on the vibration } \\
\text { plate and places hands behind the head. } \\
\text { - The subject lowers into a squat position with thighs parallel to the floor and then holds for } 20 \\
\text { seconds. }\end{array}$ \\
\hline & $\begin{array}{l}\text { Reverse dips } \\
\text { - The subject places hands shoulder-width apart on the inside edge of the vibration plate with } \\
\text { fingers flexed against the base, legs fully extended, and feet placed on the platform } 25 \mathrm{~cm} \\
\text { below the plate and then lifts the body off by fully extending arms. } \\
\text { - A repetition begins as the subject lowers the torso until the upper arms are parallel to the } \\
\text { floor and then lifts the torso back up to the starting position. }\end{array}$ \\
\hline & $\begin{array}{l}\text { Lunges } \\
\text { - The subject stands with feet shoulder-width apart on the vibration plate. } \\
\text { A repetition begins as the subject lunges backward with the foot landing on the platform } \\
\text { outside of the plate until reaching } 90 \text { degrees at both knees and then pushes the body back } \\
\text { up to the starting position. An alternate leg is used with each repetition. }\end{array}$ \\
\hline & $\begin{array}{l}\text { Flutter kicks } \\
\text { - The subject starts by lying flat on the back on the vibration plate with arms by sides and } \\
\text { palms down and extends legs fully out. } \\
\text { - A repetition begins as the subject lifts heels } 6 \text { inches above the plate and makes rapid } \\
\text { scissor-like motion with legs. One kick equals one repetition. }\end{array}$ \\
\hline & $\begin{array}{l}\text { Isometric lunges } \\
\text { - The subject stands with feet shoulder-width apart on the vibration plate. } \\
\text { The subject lunges backward with the foot landing on the platform outside of the plate until } \\
\text { reaching } 90 \text { degrees at both knees and then holds for } 20 \text { seconds. An alternate leg is used } \\
\text { with each circuit. }\end{array}$ \\
\hline & $\begin{array}{l}\text { T push-ups } \\
\text { - The subject keeps in a prone position with the back straight, the hands palms down shoulder- } \\
\text { width apart on the vibration plate. } \\
\text { - A repetition begins as the subject lowers the body until the chin nearly touches the plate and } \\
\text { then pushes the body back up while rotating one side of the body up and extending the arm } \\
\text { toward the ceiling. An alternate side is used with each repetition. }\end{array}$ \\
\hline
\end{tabular}

\section{Measurement and instrumentation}

Respiratory gas exchange indices, including $\mathrm{VO}_{2}, \mathrm{~V}_{\mathrm{E}}$, and RER, were measured in breath-bybreath using a metabolic cart (MedGraphics Corporation, St. Paul, MN). Gas analyzers were calibrated before each test using a 3-L syringe and gases provided by MedGraphics Corporation: 1) calibration gas: $5 \% \mathrm{CO}_{2}, 12 \% \mathrm{O}_{2}$, balance $\mathrm{N}_{2}$; and 2) refer- ence gas: $21 \% \mathrm{O}_{2}$, balance $\mathrm{N}_{2}$. HR was measured using a wireless HR monitor (Pacer, Polar CIC, Inc., Port Washington, NY). [La] values were assessed in duplicate via a portable lactate analyzer (Lactate Plus Meter, Nova Biomedical, Waltham, MA), and blood samples were taken from the fingertip using a sterile lancet at the baseline and immediately after each BW exercise protocol. 


\section{Statistical analysis}

$\mathrm{VO}_{2}, \mathrm{HR}, \mathrm{V}_{\mathrm{E}}$, and RER were averaged for the entire exercise protocol and the entire 30-minute post-exercise recovery, and these averages were computed for BW-V and BW+V separately. A paired $t$-test was used to compare session averages of $\mathrm{VO}_{2}, \mathrm{RER}, \mathrm{V}_{\mathrm{E}}$, and HR between BW-V and $\mathrm{BW}+\mathrm{V}$ for the entire exercise session as well as for the recovery period. $\mathrm{VO}_{2}, \mathrm{HR}$, and repetitions completed were also averaged for each individual exercise across the three circuits. A two-way (condition by exercise) ANOVA with repeated measures was used to examine how vibration may affect each BW exercise differently. Additionally, a one-way ANOVA with repeated measures was used to compare [La] across the baseline and at the end of $\mathrm{BW}-\mathrm{V}$ and $\mathrm{BW}+\mathrm{V}$. A significant $\mathrm{F}$ ratio was followed by post-hoc comparisons to detect pairwised differences using Bonferroni's adjustments. A probability level of .05 was established to denote statistical significance. All analyses were carried out using the Statistical Package for the Social Sciences (SPSS Version 23, SPSS, Inc. Chicago, IL).

\section{Results}

$\mathrm{V}_{\mathrm{E}}$ was significantly greater $(\mathrm{p}=.031)$ in $\mathrm{BW}+\mathrm{V}$ than $\mathrm{BW}-\mathrm{V}$, while no significant differences were seen for $\mathrm{VO}_{2}$, RER, and HR between the two conditions (Table 3). The mean $\mathrm{VO}_{2}$ reached 22.11 \pm 0.51 and $23.28 \pm 0.82 \mathrm{ml} \cdot \mathrm{kg}^{-1} \cdot \mathrm{min}^{-1}$ and these values corresponded to approximately $48 \%$ and $50 \%$ of $\mathrm{VO}_{2} \max$ in $\mathrm{BW}-\mathrm{V}$ and $\mathrm{BW}+\mathrm{V}$, respectively. The mean $\mathrm{HR}$ reached $156.63 \pm 4.15$ and $162.22 \pm 4.40$ beat $\cdot \mathrm{min}^{-1}$ and these values corresponded to approximately $80 \%$ and $83 \%$ of HRmax in $\mathrm{BW}-\mathrm{V}$ and $\mathrm{BW}+\mathrm{V}$, respectively.

One-way ANOVA revealed a significant main effect for $[\mathrm{La}]\left(\mathrm{F}_{2,26}=95.05, \mathrm{p}=.000, \mathrm{~h}^{2}=.88\right)$.

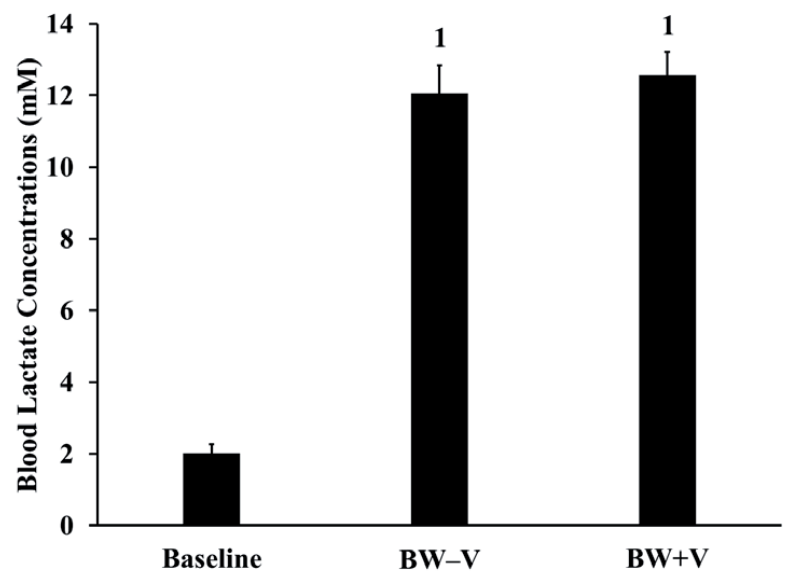

Figure 1. Blood lactate concentrations at baseline and at the end of body-weight exercise with $(B W+V)$ and without vibration $(B W-V)$. Data are means $\pm S E$. "Significantly greater than the baseline, $p<.05$.

Compared to the baseline, [La] values were significantly elevated in both $\mathrm{BW}-\mathrm{V}$ and $\mathrm{BW}+\mathrm{V}$ (Figure 1). The peak $[\mathrm{La}]$ reached at the end of $\mathrm{BW}-\mathrm{V}$ and $\mathrm{BW}+\mathrm{V}$ were $12.1 \pm 0.8$ and $12.6 \pm 0.6 \mathrm{mM}$, respectively. However, no differences in [La] were observed between the two conditions.

During 30-minute of recovery following exercise, $\mathrm{VO}_{2}$ was significantly greater $(t=3.991, \mathrm{p}=.002)$, whereas RER was significantly lower $(t=2.385$, $\mathrm{p}=.033$ ) in $\mathrm{BW}+\mathrm{V}$ than $\mathrm{BW}-\mathrm{V}$ (Table 4$)$. No significant differences were observed for $V_{E}$ and $H R$.

There was a significant interaction between condition and exercise for $\mathrm{VO}_{2}\left(\mathrm{~F}_{7,91}=2.56, \mathrm{p}=.019\right.$, $\left.\mathrm{h}^{2}=.17\right)$ and $\mathrm{HR}\left(\mathrm{F}_{7,91}=2.34, \mathrm{p}=.044, \mathrm{~h}^{2}=.014\right)$. These findings suggest that vibration would affect cardiometabolic responses during each exercise differently. Post-hoc comparisons revealed significantly higher $\mathrm{VO}_{2}$ during prisoner squat $(\mathrm{p}=.003)$ and isometric squat $(\mathrm{p}=.042)$ and a significantly higher

Table 3. Mean cardiorespiratory and metabolic responses during body-weight exercises with $(B W+V)$ and without (BW-V) vibration

\begin{tabular}{lcccc}
\hline Variables & BW-V & BW+V & p value & Effect size $($ Cohen's $d)$ \\
\hline $\mathrm{VO}_{2}\left(\mathrm{ml}^{\prime} \mathrm{kg}^{-1} \cdot \mathrm{min}^{-1}\right)$ & $22.11 \pm 0.51$ & $23.28 \pm 0.82$ & 0.069 & 0.50 \\
$\mathrm{HR}\left(\right.$ beats $\left.\cdot \mathrm{min}^{-1}\right)$ & $156.63 \pm 4.15$ & $162.22 \pm 4.10$ & 0.080 & 0.47 \\
$\mathrm{~V}_{\mathrm{E}}\left(\mathrm{l} \cdot \mathrm{min}^{-1}\right)$ & $58.39 \pm 4.16$ & $63.223 \pm 3.90$ & $0.031^{*}$ & 0.65 \\
$\mathrm{RER}$ & $1.10 \pm 0.02$ & $1.10 \pm 0.02$ & 0.426 & 0.01 \\
\hline
\end{tabular}

Note. Data are mean \pm SE. *Statistically significant, $p<.05$.

Table 4. Mean cardiorespiratory and metabolic responses during 30-min recovery following body-weight exercises with (BW+V) and without $(B W-V)$ vibration

\begin{tabular}{lcccc}
\hline Variables & BW-V & BW+V & p value & Effect size $($ Cohen's $d)$ \\
\hline $\mathrm{VO}_{2}\left(\mathrm{ml}^{\prime} \mathrm{kg}^{-1} \cdot \mathrm{min}^{-1}\right)$ & $8.44 \pm 0.29$ & $9.06 \pm 0.31$ & $0.002^{*}$ & 1.06 \\
$\mathrm{HR}($ beat $\cdot \mathrm{min}-1)$ & $105.86 \pm 4.11$ & $108.85 \pm 3.59$ & 0.137 & 0.42 \\
$\mathrm{~V}_{\mathrm{E}}\left(\mathrm{l} \cdot \mathrm{min}^{-1}\right)$ & $24.07 \pm 2.20$ & $25.58 \pm 2.19$ & 0.091 & 0.49 \\
$\mathrm{RER}$ & $0.94 \pm 0.02$ & $0.89 \pm 0.02$ & $0.033^{*}$ & 0.64 \\
\hline
\end{tabular}

Note. Data are mean \pm SE. *Statistically significant, $p<.05$. 
Table 5. Exercise-specific comparisons of oxygen uptake, heart rate, and repetitions completed between vibration $(B W+V)$ and no vibration $(B W-V)$ condition

\begin{tabular}{|c|c|c|c|c|}
\hline Variables & Exercises & BW-V & $B W+V$ & $p$ value \\
\hline \multirow{8}{*}{$\begin{array}{l}\mathrm{VO}_{2} \\
\left(\mathrm{ml} \cdot \mathrm{kg}^{-1} \cdot \mathrm{min}^{-1}\right)\end{array}$} & Prisoner squat & $13.49 \pm 0.56$ & $15.17 \pm 0.65$ & $0.001^{*}$ \\
\hline & Push-up & $20.03 \pm 0.73$ & $20.66 \pm 3.31$ & 0.123 \\
\hline & Isometric squat & $23.16 \pm 0.40$ & $24.37 \pm 0.78$ & $0.031^{*}$ \\
\hline & Reverse dip & $21.16 \pm 0.48$ & $22.99 \pm 1.22$ & 0.075 \\
\hline & Lunge & $26.66 \pm 0.77$ & $26.95 \pm 1.07$ & 0.341 \\
\hline & Flutter kicks & $26.77 \pm 0.83$ & $28.11 \pm 1.19$ & 0.073 \\
\hline & Isometric lunge & $22.95 \pm 0.51$ & $22.92 \pm 1.05$ & 0.489 \\
\hline & T push-up & $22.65 \pm 0.71$ & $21.63 \pm 0.99$ & 0.062 \\
\hline \multirow{8}{*}{$\begin{array}{l}\text { HR } \\
\text { (beats·min-1) }\end{array}$} & Prisoner squat & $141.60 \pm 4.74$ & $150.43 \pm 6.05$ & 0.084 \\
\hline & Push-up & $154.14 \pm 4.86$ & $156.19 \pm 7.45$ & 0.115 \\
\hline & Isometric squat & $145.57 \pm 4.94$ & $153.45 \pm 4.84$ & $0.010^{*}$ \\
\hline & Reverse dip & $156.43 \pm 6.62$ & $164.64 \pm 4.50$ & 0.086 \\
\hline & Lunge & $164.26 \pm 3.32$ & $167.74 \pm 4.04$ & 0.162 \\
\hline & Flutter kicks & $162.33 \pm 4.05$ & $168.36 \pm 4.18$ & 0.074 \\
\hline & Isometric lunge & $158.50 \pm 4.69$ & $160.90 \pm 5.79$ & 0.324 \\
\hline & T push-up & $166.60 \pm 3.92$ & $171.98 \pm 4.01$ & 0.094 \\
\hline \multirow{8}{*}{$\begin{array}{l}\text { Repetitions completed } \\
\left(\text { rep } \text { circuit }^{-1} \text { ) }\right.\end{array}$} & Prisoner squat & $18.3 \pm 0.9$ & $18.0 \pm 0.8$ & 0.250 \\
\hline & Push-up & $20.3 \pm 2.0$ & $20.7 \pm 1.9$ & 0.236 \\
\hline & Isometric squat & N/A & $\mathrm{N} / \mathrm{A}$ & $N / A$ \\
\hline & Reverse dip & $23.4 \pm 1.5$ & $23.2 \pm 1.5$ & 0.218 \\
\hline & Lunge & $13.5 \pm 0.6$ & $13.2 \pm 0.7$ & 0.213 \\
\hline & Flutter kicks & $58.5 \pm 4.0$ & $58.3 \pm 3.1$ & 0.445 \\
\hline & Isometric lunge & $\mathrm{N} / \mathrm{A}$ & $\mathrm{N} / \mathrm{A}$ & N/A \\
\hline & T push-up & $9.4 \pm 0.6$ & $9.4 \pm 0.6$ & 0.447 \\
\hline
\end{tabular}

Note. Data are mean \pm SE. *Statistically significant, $p<.05$.

HR $(\mathrm{p}=.020)$ during isometric squat in $\mathrm{BW}+\mathrm{V}$ than $\mathrm{BW}-\mathrm{V}$, while no differences in $\mathrm{VO}_{2}$ and $\mathrm{HR}$ between the two conditions were observed for all other exercises (Table 5). For all the exercises, the repetitions completed remained similar between $\mathrm{BW}-\mathrm{V}$ and $\mathrm{BW}+\mathrm{V}$.

\section{Discussion and conclusions}

One of the major findings is that in $\mathrm{BW}+\mathrm{V}$ and $\mathrm{BW}-\mathrm{V}$, the average $\mathrm{VO}_{2}$ reached 22 and 23 $\mathrm{ml} \cdot \mathrm{kg}^{-1} \cdot \mathrm{min}^{-1}$ or $48 \%$ and $50 \%$ of $\mathrm{VO}_{2}$ max, respectively, and the average HR reached 157 and 162 beat $\min ^{-1}$ or $80 \%$ and $83 \%$ of HRmax, respectively. These results suggest that a BW exercise protocol performed using Tabata intervals could increase cardiorespiratory and metabolic responses to the level that surpasses the upper end of moderate intensity range (i.e., $\sim 6$ METs) as defined by American College of Sports Medicine (Garber, et al. 2011). Our findings are comparable with those of Ratamess et al., (2015) who found that three sets of 10 repetitions of burpees and push-ups with lateral crawl with a 2-minute rest between sets produced average $\mathrm{VO}_{2}$ of
22.9 and $19.5 \mathrm{ml} \cdot \mathrm{kg}^{-1} \cdot \mathrm{min}^{-1}$, respectively. The metabolic demand elicited by the current protocol was lower than that of Emberts, Porcari, Dobers-Tein, Steffen, and Foster (2013) who used the similar work-rest ratio but reported an average $\mathrm{VO}_{2}$ of $34.8 \mathrm{ml} \cdot \mathrm{kg}^{-1} \cdot \mathrm{min}^{-1}$ or $74 \%$ of $\mathrm{VO}_{2}$ max predicted. The BW exercise protocol used by Emberts et al. (2013) included the burpee, high knee run, jump rope, and jumping jack exercises, all of which may involve more muscle mass than the ones used presently. Nevertheless, neither of the exercises used by Emberts et al., (2013) was chosen in the present study due to logistic difficulty of performing on a vibration plate. In fact, two of the eight exercises used presently were static exercises, i.e., isometric squat and isometric lunge. It has been reported that energy cost of performing a given external load is lower during static than dynamic exercise (Danoff \& Danoff, 1982; Elder, Mahoney, Black, Slade, \& Dudley, 2006). Indeed, there are a variety of BW exercises that can be chosen, but the resulting metabolic demand can vary greatly depending upon muscle mass involvement, muscle action (i.e., dynamic vs. isometric), movement velocity, sets and 
repetitions, and work-rest ratio. Our data indicated that performing BW exercises in a rapid and intermittent manner can make the workout challenging enough to meet or exceed the moderate intensity threshold.

Another important feature of the BW exercise protocol found in the present study is that it involved anaerobic metabolism. This is evidenced by the fact that [La] increased significantly averaging at approximately $12 \mathrm{mM}$ and the mean RER reached 1.1 throughout the entire exercise period in both $\mathrm{BW}-\mathrm{V}$ and $\mathrm{BW}+\mathrm{V}$. [La] typically reach between 8 and $10 \mathrm{mM}$ at volitional exhaustion during a graded exercise test (Powers \& Howley 2018). A RER $>1$ results mainly from respiratory compensation in an effort to maintain a normal $\mathrm{pH}$. A similar peak [La] (i.e., $\sim 12 \mathrm{mM}$ ) was shown by Emberts et al. (2013) who used BW exercises in conjunction with Tabata intervals. Similarly, Ratamess et al., (2015) reported an average RER of $>1$ during the burpee, push-up, BOSU push-up, and push-up with lateral crawl exercises with each exercise being performed in three sets of 10-20 repetitions with 2 -minute rest between sets. The significant involvement of anaerobic metabolism in this protocol can be largely attributed to the Tabata intervals used to carry out the protocol. The Tabata interval structure entails repeated and shorter (i.e., 20 s) bursts of all-out exercises with limited rest intervals (i.e., 10 s) between exercises (Tabata, et al., 1996, 1997). By using this intense interval training format on a cycle ergometer five days a week for six weeks among physically active individuals, Tabata et al. (1996) demonstrated a 28\% improvement in anaerobic capacity as determined by maximal accumulated oxygen deficit.

Intense nature of the current $\mathrm{BW}$ exercise protocol can also be explained by comparing our results on post-exercise $\mathrm{VO}_{2}$ with those of earlier investigations. The present study demonstrated that the mean $\mathrm{VO}_{2}$ during 30 min of recovery period was 8.44 and $9.06 \mathrm{ml} \cdot \mathrm{kg}^{-1} \cdot \mathrm{min}^{-1}$ in BW-V and BW+V, respectively. In an earlier study by Ratamess et al. (2018), who measured metabolic cost of a treadmill run at $60 \% \mathrm{VO}_{2}$ reserve for a duration similar to the current protocol, the mean $\mathrm{VO}_{2}$ during 30-minute recovery was $\sim 7 \mathrm{ml} \cdot \mathrm{kg}^{-1} \cdot \mathrm{min}^{-1}$ or $20-25 \%$ lower than what was found presently. In this same study, the mean $\mathrm{VO}_{2}$ and peak [La] during the run were 30.3 $\mathrm{ml} \cdot \mathrm{kg}^{-1} \cdot \mathrm{min}^{-1}$ and $3.6 \mathrm{mM}$, respectively. The greater post-exercise metabolic response seen presently as compared to treadmill running can be largely attributed to the greater anaerobic contribution during the BW exercise protocol discussed earlier.

In the present study, we found no significant differences in $\mathrm{VO}_{2}$ between $\mathrm{BW}-\mathrm{V}$ and $\mathrm{BW}+\mathrm{V}$. This finding seems to disagree with our previous studies in which we found a significant increase in $\mathrm{VO}_{2}$ during body-weight squat in response to the same vibratory stimulus (Kang, et al., 2016b). It should be noted that the metabolic effect of vibration has been typically shown during exercise such as BW squat in which a vibration plate served as a full base of support (DaSilva, et al., 2007; Garatachea, et al., 2007; Kang, et al., 2016a, 2016b; Rittweger, et al., 2001, 2002). In the present study, however, we tested an overall effect of the eight different BW exercises performed successively, and all but three (i.e., prisoner squat, isometric squat, and flutter kicks) were carried out with the body being supported by both a vibration plate and the floor simultaneously. It appears that an additional support from the floor may have functioned to dampen vibratory transmission in the body, although this theory needs to be further examined. The lack of vibratory effect may also be attributed to the BW exercise protocol. In this study, the BW exercise protocol was done in a rapid and intermittent manner and thus more demanding metabolically than the isolated BW squats used by earlier studies. As a result, the relative contribution of vibration to the overall metabolic demand of the protocol would be less, which could make the detection of vibration effect more difficult. Interestingly, as shown in Table 5, a significant increase in $\mathrm{VO}_{2}$ was revealed for the prisoner squat and the isometric squat, whereas most of other exercises only demonstrated a marginal increase in the vibration condition. These results suggest that the metabolic efficacy of vibration can be influenced by how BW exercises are carried out concurrently with a vibration plate.

Interestingly, $\mathrm{V}_{\mathrm{E}}$ was increased by vibration while $\mathrm{VO}_{2}, \mathrm{HR}$, RER remained relatively unchanged. This finding would suggest that factors other than metabolic demand may have mediated the increase in $V_{E}$ under the vibration condition. The greater $V_{E}$ can result from a greater respiratory compensation in response to prevailing metabolic acidosis. However, this explanation is unlikely because [La] and RER were similar between $\mathrm{BW}+\mathrm{V}$ and $\mathrm{BW}-\mathrm{V}$. The greater $\mathrm{V}_{\mathrm{E}}$ in $\mathrm{BW}+\mathrm{V}$ may simply be the result of vibratory stimulation. This is because vibration elicits muscle reflexes that involve muscle spindles (Rittweger, Beller, \& Felsenberg, 2000) and activation of these mechanoreceptors has been shown to increase pulmonary ventilation (Mahler, 1979; McCloskey \& Mitchell,1972). However, this speculation remains to be substantiated as such ventilatory activation should also be associated with a concomitant increase in metabolic demand or $\mathrm{VO}_{2}$, which was not the case in this study.

The mean $\mathrm{VO}_{2}$ was significantly higher during 30-minute recovery following exercise in $\mathrm{BW}+\mathrm{V}$ than BW-V (Table 4). This finding seems to corroborate our earlier study in which we found that the vibration-induced increase in $\mathrm{VO}_{2}$ persisted through the early portion of aerobic exercise that commenced immediately after the vibration treat- 
ment(Kang, et al., 2016a, 2016b). Reason as to why the metabolic effect of vibration was manifested only during recovery is not readily available. We discerned that this could be due to the intense and complex nature of the BW exercise protocol used presently. It appears that the metabolic effect of vibration can be more easily detected in less metabolically challenging conditions such as rest or low intensity exercises. Interestingly, RER during recovery was significantly lower under the vibration condition. A lower RER would suggest that a greater percentage of energy is being derived from fat. However, given that the overall metabolic effect of vibration was rather small, it seems unlikely that such favorable metabolic pattern post vibration would help in producing a meaningful weight loss.
In conclusion, this is the first study that has examined the interactive effect of BW exercises and vibration on cardiometabolic responses. Given a growing interest in BW exercises (Thompson, 2016, 2017), findings of this study will have implication for how BW exercises may be best implemented in conjunction with vibration. Our results demonstrated that performing three circuits of eight BW exercises in a rapid and intermittent manner elicited sufficient increases in cardiometabolic responses both during and after exercise. Adding vibration to BW exercises may provide additional metabolic benefits when a vibration plate serves as a full base of support during exercise. However, metabolic efficacy of using a multimodal BW exercise protocol in which the body is partially supported by a vibration plate remains to be further investigated.

\section{References}

Bosco, C., Cardinale, M., \& Tsarpela, O. (1999). Influence of vibration on mechanical power and electromyogram activity in human arm flexor muscles. European Journal of Applied Physiology, 79, 306-311.

Buckley, S., Knapp, K., Lackie, A., Lewry, C., Horvey, K., Benko, C., Trinh, J., \& Butcher, S. (2015). Multimodal highintensity interval training increases muscle function and metabolic performance in females. Applied Physiology, Nutrition, and Metabolism, 40, 1157-1162.

Cardinale, M., \& Lim, J. (2003). Electromyography activity of vastuslateralis muscle during whole-body vibrations of different frequencies. Journal of Strength and Conditioning Research, 17, 621-624.

Carter, S.E., Jones, M., \& Gladwell, V.F. (2015). Energy expenditure and heart rate response to breaking up sedentary time with three different physical activity interventions. Nutrition, Metabolism and Cardiovascular Diseases, 25, 503-509.

Cochrane, D.J. (2011). Vibration exercise: the potential benefits. International Journal of Sports Medicine, 32 , 75-99.

Danoff, P.L., \& Danoff, J.V. (1982). Energy cost and heart rate response to static and dynamic leg exercise. Archive of Physical Medicine and Rehabilitation, 63, 130-134.

DaSilva, M.E., Fernandez, J.M., Castillo, E., Nuñez, V.M., Vaamonde, D.M., Poblador, M.S., \& Lancho, J.L. (2007). Influence of vibration training on energy expenditure in active men. Journal of Strength and Conditioning Research, 21, 470-475.

Elder, C.P., Mahoney, E.T., Black, C.D., Slade, J.M., \& Dudley, G.A. (2006). Oxygen cost of dynamic or isometric exercise relative to recruited muscle mass. Dynamic Medicine, $5,9$.

Emberts, T., Porcari, J., Dobers-Tein, S., Steffen, J., \& Foster, C. (2013). Exercise intensity and energy expenditure of a Tabata workout. Journal of Sports Science and Medicine, 12, 612-613.

Garatachea, N., Jiménez, A., Bresciani, G., Mariño, N.A., González-Gallego, J., \& de Paz, J.A. (2007). The effects of movement velocity during squatting on energy expenditure and substrate utilization in whole-body vibration. Journal of Strength and Conditioning Research, 21, 594-598.

Garber, C.E., Blissmer, B., Deschenes, M.R., Franklin, B.A., Lamonte, M.J., Lee, I.M., Nieman, D.C., \& Swain, D.P. American College of Sports Medicine. American College of Sports Medicine position stand. (2011). Quantity and quality of exercise for developing and maintaining cardiorespiratory, musculoskeletal, and neuromotor fitness in apparently healthy adults: guidance for prescribing exercise. Medicine and Science in Sports Exercise, $43,1334-1359$.

Giombini, A., Macaluso, A., Laudani, L., Di Cesare, A., Piccinini, A., Pigozzi, F., \& Saraceni, V.M. (2013). Acute effect of whole-body vibration at optimal frequency on muscle power output of the lower limbs in older women. American Journal of Physical Medicine and Rehabilitation, 92, 797-804.

Jackson, A., \& Pollock, M. (1978). Generalized equations for predicting body density of men. British Journal of Nutrition, 40, 497-504.

Jackson, A., Pollock, M., \& Ward, A. (1980). Generalized equations for predicting body density of women. Medicine Science in Sports Exercise, 12, 175-182.

Kang, J., Bush, J.A., Ratamess, N.A., Faigenbaum, A.D., Klei, S., Macroni, D., \& Kreckel, M. (2016a). Acute effects of whole-body vibration on energy metabolism during aerobic exercise. Journal of Sports Medicine and Physical Fitness, 56, 834-842. 
Kang, J., Porfido, T., Ismaili, C., Selamie, S., Kuper, J., Bush, J.A., Ratamess, N.A., \& Faigenbaum, A.D. (2016b). Metabolic responses to whole-body vibration: effect of frequency and amplitude. European Journal of Applied Physiology, 116, 1829-1839.

Kendall, K.L., \& Fairman, C.M. (2014). Women and exercise in aging. Journal of Sports and Health Science, 3, 170-178.

Luo, J., McNamara, B., \& Moran, K. (2005). The use of vibration training to enhance muscle strength and power. Sports Medicine, 35, 23-41.

Mahler, M. (1979). Neural and humoral signals for pulmonary ventilation arising in exercising muscle. Medicine and Science in Sports, 11, 191-197.

Marín, P.J., \& Rhea, M.R. (2010a). Effects of vibration training on muscle power: a meta-analysis. Journal of Strength and Conditioning Research, 24, 871-878.

Marín, P.J., \& Rhea, M.R. (2010b). Effects of vibration training on muscle strength: a meta-analysis. Journal of Strength and Conditioning Research, 24, 548-556.

McCloskey, D.I., \& Mitchell, J.H. (1972). Reflex cardiovascular and respiratory responses originating in exercising muscle. Journal of Physiology, 224, 173-186.

McRae, G., Payne, A., Zelt, J.G., Scribbans, T.D., Jung, M.E., Little, J.P., \& Gurd, B.J. (2012). Extremely low volume, whole-body aerobic-resistance training improves aerobic fitness and muscular endurance in females. Applied Physiology, Nutrition, and Metabolism, 37, 1124-1131.

Myers, T.R., Schneider, M.G., Schmale, M.S., Hazell, T.J. (2015). Whole-body aerobic resistance training circuit improves aerobic fitness and muscle strength in sedentary young females. Journal of Strength and Conditioning Research, 29, 1592-1600.

Powers, S.K., \& Howley, E. (2018). Exercise tests to evaluate cardiorespiratory fitness. In Exercise Physiology: Theory and Application to Fitness and Performance (pp. 344-360), 10 ${ }^{\text {th }}$ ed. New York, NY: McGraw Hill.

Ratamess, N.A., Kang, J., Kuper, J.D., O’Grady, E.A., Ellis, N.L., Vought, I.T., Culleton, E., Bush, J.A., \& Faigenbaum, A.D. (2018). Acute metabolic and cardiovascular effects of a sandbag resistance exercise protocol. Journal of Strength and Conditioning Research, 32, 1491-1502.

Ratamess, N.A., Rosenberg, J.G., Klei, S., Dougherty, B.M., Kang, J., Smith, C.R., Ross, R.E., \& Faigenbaum, A.D. (2015). Comparison of the acute metabolic responses to traditional resistance, body-weight, and battling rope exercises. Journal of Strength and Conditioning Research, 29, 47-57.

Rittweger, J. (2010). Vibration as an exercise modality: how it may work, and what its potential might be. European Journal of Applied Physiology, 108, 877-904.

Rittweger, J., Beller, G., \& Felsenberg, D. (2000). Acute physiological effects of exhaustive whole-body vibration exercise in man. Clinical Physiology, 20, 134-142.

Rittweger, J., Ehrig, J., Just, K., Mutschelknauss, M., Kirsch, K.A., \& Felsenberg, D. (2002). Oxygen uptake in wholebody vibration exercise: Influence of vibration frequency, amplitude, and external load. International Journal of Sports Medicine, 23, 428-432.

Rittweger, J., Schiessl, H., \& Felsenberg, D. (2001). Oxygen uptake during whole-body vibration exercise: Comparison with squatting as a slow voluntary movement. European Journal of Applied Physiology, 86, 169-173.

Seguin, R., \& Nelson, M.E. (2003). The benefits of strength training for older adults. American Journal of Preventive Medicine, 25(Supplement 2), 141-149.

Siri, W.E. (1956). Gross composition of the body. In J.H. Lawrence \& C.A. Tobias (Eds.), Advances in Biological and Medical Physics, IV (pp. 239-279). New York, NY: Academic Press.

Tabata, I., Irisawa, K., Kouzaki, M., Nishimura, K., Ogita, F., \& Miyachi, M. (1997). Metabolic profile of high intensity intermittent exercises. Medicine and Science in Sports Exercise, 29, 390-395.

Tabata, I., Nishimura, K., Kouzaki, M., Hirai, Y., Ogita, F., Miyachi, M., \& Yamamoto, K. (1996). Effects of moderateintensity endurance and high-intensity intermittent training on anaerobic capacity and $\mathrm{VO}_{2} \max$. Medicine and Science in Sports and Exercise, 28, 1327-1330.

Thompson, W.R. (2016). Worldwide survey of fitness trends for 2016. ACSM's Health and Fitness Journal, 19, 9-18. Thompson, W.R. (2017). Worldwide survey of fitness trends for 2017. ACSM's Health and Fitness Journal, 20 , 8-17.

Submitted: April 7, 2018

Accepted: June 26, 2018

Published Online First: March 25, 2019

Correspondence to:

Jie Kang, Ph.D., FACSM

Department of Health and Exercise Science

The College of New Jersey

Ewing, NJ 08628, USA

Tel.: 609 771-2848

Fax: 609-637-5153

E-mail: kang@tcnj.edu 